\title{
PROCESSED PRODUCTS OF TERMITES AND LAKE FLIES: \\ IMPROVING ENTOMOPHAGY FOR FOOD SECURITY WITHIN THE LAKE VICTORIA REGION
}

\section{Ayieko MA*1, Oriaro $\mathrm{V}^{2}$ and IA Nyambuga ${ }^{3}$}

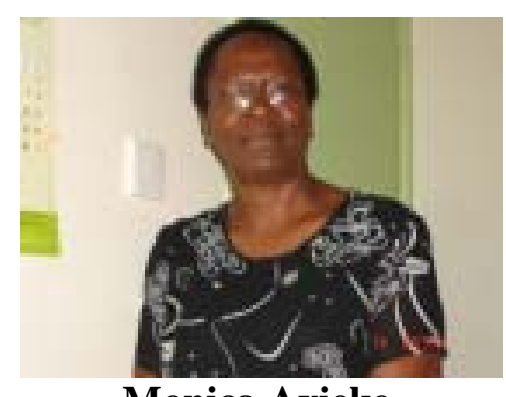

Monica Ayieko

*Corresponding author email: monica_ayieko@yahoo.com

${ }^{1}$ Family and Consumption Economist, Department of Ecotourism, Hotel and Institution Management, Maseno University, Maseno, Kenya

${ }^{2}$ Community Nutrition and Dietetics program, School of Public Health and Community Development, Maseno University, Maseno Kenya

${ }^{3}$ Hospitality Management, Department of Ecotourism, Hotel and Institution Management, Maseno University, Maseno, Kenya 


\begin{abstract}
Among the factors contributing to food shortage in Africa are lack of appropriate preservation and storage facilities, tropical heat and poor road network for marketing produce. High food spoilage caused by high temperatures of the tropical areas necessitates storage for all householders. Marginal areas of Lake Victoria often suffer protein deficiency due to dependence on narrow base sources of protein, most of which get spoilt during storage. The lake region is endowed with plenty of edible insects. Edible insects can provide partial solution to food insecurity. The aim of this project was to promote entomophagy for food security by adding value to termites and lake flies, enhancing taste and preference of edible insects, and improving shelf life of edible insect products in marginal areas with food insecurity. Two specific objectives examined were to add value by processing termites and lake flies into readily acceptable consumer products; and to test acceptability of processed products of termites and lake flies across different audiences. Samples of termites and lake flies were collected and processed in the laboratory under different types of cooking methods such as baking, boiling and steam cooking under pressure. The processed products included crackers, muffins, sausages and meat loaf. The products were tested among convenient sampled respondents. Processing the products added value based on organoleptic tests and minimized the fear of eating insects among many people. Not only marginal areas with limited protein foods but all areas with these insects can improve their food situation by value adding to these available resources. Mostly, people are familiar with these insects, therefore, the processed products of lake flies and termites were readily accepted, which could make their commercialization easier. It was concluded that processing edible insects into conventional consumer products encourages entomophagy and has potential for income generation and food security within the lake region.
\end{abstract}

Key words: Entomophagy, Termites, Lakeflies, Edible insects 


\section{INTRODUCTION}

Use of edible insects as human food goes back to the dawn of mankind [1]. The Bible talks about certain insects as kosher foods [2]. Bodenheumer [3] is credited with first presentation of a global review of insects as food. Literature documents edible insects as rich in essential food nutrients necessary for human and livestock feeding $[4,5,6$, 7, 8, and 9]. An edited book has been published with several authors discussing potential of insects as minilivestock [10]. The FAO conference held in Chiang Mai Thailand in 2008 unanimously recommended popularization of edible insects as an option for increasing sources of foods in the world [11]. Consumption of edible insects is, thus, not a new idea. It is how the insects are served that is new in food science. Scientists now have the challenge to find means and ways of popularizing the use of the abundant edible insects, thus the focus of this article.

It is now common knowledge that among the factors contributing to food shortage in Third World countries is lack of appropriate preservation and storage facilities at the household level as observed in many rural homes without electricity. During harvesting, there is a good supply of food produce, which is short lasting due to lack of appropriate storage facilities at the household level. Poor road network and inaccessible trade centers inhibit effective food distribution to families without adequate storage $[12,13]$. High food spoilage caused by high temperatures of the tropical areas necessitates effective storage for all households. Further, many parts of the world such as marginal areas of the Lake Victoria region often suffer lack of adequate protein in the diet due to heavy dependence on narrow base sources of protein, which is contributed by limited agricultural and livestock production [14].

The lake region is endowed with plenty of edible insects such as termites, grasshoppers, locusts and a collection of edible lake flies. Termites are abundant in Africa and provide a great mass of material possessing genuine food value for both human and livestock. The major limiting factor in the use of edible insects is that they are seasonal and highly perishable. Villagers have come to believe that the insects such as termites and lake flies, which are of interest in this project, come in plenty but can only be utilized a day or two after collection. This study seeks to show that the insects can be processed by conventional cooking methods for a longer shelf life at the household level.

The food situation in Africa is made worse by lack of ideas for income generation due to limited natural resources and frequent severe weather conditions. This study aims at showing that the Lake Victoria region has edible insects that can be utilized to feed families, livestock and for income generation. Although, many insects have been blamed for lowering the capacity of rural communities to produce adequate foods, termites and lake flies have formed part of the diet of many families along the lake region for centuries [15]. These insects actually improve soil structure and are the major components of biodiversity and should be appreciated [16]. Edible insects could make a difference to levels of poverty and food security in many homes in Africa.

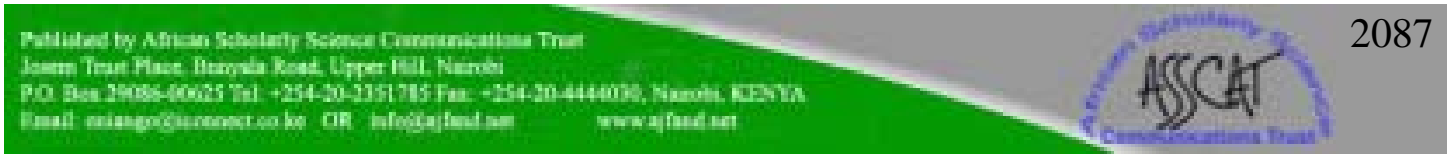


By means of qualitative descriptive methods, this study, therefore, attempted processing edible insects to add value to increase their demand, capacity and willingness of a wider audience to consume. The ultimate goal of this project is to increase sources of food protein and income generation for poverty alleviation and to promote management of the biodiversity that supports the insects in the Arid and Semi Arid Land (ASAL), and the lake region.

Diptera (Chaoboridae and Chironomidae) and Ephimeroptera form the lake fly group commonly eaten within the lake region. Although Mayfly is the common name of ephemeroptera, chaoboridae and chironomidae are referred to as mayflies by the villagers simply because of their spectacular characteristic month of May emergence. In the local Luo dialect of the Lake Victoria region they are known as Sam. The lake flies are confined within the shores of the lake while the termites are also found within the hinterlands. The lake flies are important in constituting part of fish food in lakes and rivers. The insects normally emerge from lakes, streams or rivers in huge numbers and the dead adults accumulate in large piles. The flies are familiar to people who spend much of their time around fresh waters such as lakes and rivers. The life span is usually short, lasting from several hours to a day, during which they gather in huge swarms to mate [16].

Termites, Isoptera termitidae (known as $\mathrm{Ng}^{\prime}$ wen in Luo, Kumbekumbe in Swahili and Tsiswa in Luhya dialects in Kenya) appear to be of greater significance in diets than most ants [17]; however, their seasonality inhibits regular collection throughout the year. The most popular are the sexual winged forms of the larger species within low lands. These emerge from holes at the mounds after the first rains and during the short rains, late during the last quarter of the year. The abundance of the insects may vary widely from year to year due to over-exploitation of the environment [5]. Although termite harvest begins with the onset of the rains and swarming of the sexuals, villagers have shown that some termites could be induced to emerge, particularly during the short rains. This is a common practice with many villagers who have mastered the art of collecting termites. Termites are widely found within the lake region, but are also available in the hinterlands in limited amounts due to higher altitudes, which do not support the large edible species.

The purpose of this project was to explore possibilities of processing termites and lake flies into current consumer products to promote entomophagy. Specific objectives examined were to add value by processing termites and lake flies into readily acceptable consumer products and to test acceptability of processed products of termites and lake flies.

\section{MATERIALS AND METHODS}

Three types of edible insects were collected along the Lake Victoria region for the study. These were Ephimeroptera, Diptera and Isoptera. The lake flies were collected from Suba and Bondo districts while the termites came from Siaya and Kisumu

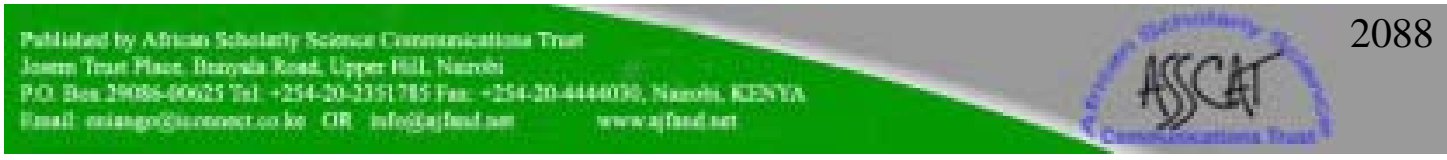


districts of Nyanza province, Kenya. Termites and lake flies are normally available in plenty and are the most accepted as human food in these communities.

Samples of lake flies and termites were collected using traditional harvesters. The harvester for lake flies is a woven basket, which is tied to one end of a three-meter long stick. By holding the other end of the stick, the basket is whirled in the air to collect the insects when the insects are in flight. Termites were collected at night by trapping them with a source of light placed in a plastic basin or bucket. The insects were then dipped in boiling water, drained and spread out to dry in the sun. Some were roasted in a pan to dry them out.

\section{Processing - Value adding}

The insects were either roasted or sun dried, ground, and mixed with other ingredients for cooking using different conventional cooking methods. The conventional cooking methods included baking, boiling and pressure-cooking. Simple basic methods of baking crackers and muffins without using chemical preservatives or essence were used. Several trials of dough making were made before arriving at an acceptable constituent. The sausage constituent portions were boiled while the meat loaf was cooked under pressure. After several trials and testing, a total of six preferred items were made. These were: 1) Termite crackers, 2) Mayfly crackers, 3) Termite muffins, 4) Mayfly muffins, 5) Mayfly meat loaf, and 6) Mayfly sausages. The filling materials for all the products included wheat and bread crumbs. For binding, commercial gelatin and eggs were used in proportionate amounts whereas only sugar and salt were added for flavor.

Purposive sampling of testers was used to include target clients for entomophagy, who would influence other future potential consumers. Two stages of product testing were adopted. The products were first tested in the lab among sampled clients who had previously eaten the insects as well as those who had never eaten the insects before. This facilitated identification of the most acceptable prototype products from a total of 12 to the final six products. The second product testing was done with a larger audience. A workshop on product release awareness was held at the Maseno University for students and staff. A total of 35 participants tasted and gave their opinion on taste, appearance and aroma.

The 12 different types of products were made within a period of one month at different days in the lab. Several respondents were, therefore, invited on different days to try them out in the lab. The respondents were encouraged to give their true opinion of the product taste and flavor, smell, appearance and overall preference of only one product of their choice. The respondents summarized their feed back into 'Product OK', 'Product not OK', and 'My best of all' based on the organoleptic tests as shown in the Table 1. 


\section{RESULTS}

Table 1 shows the outcome of the product testing. Termite crackers received the most favorable response. Termite crackers, muffins and Mayfly meat loaf were rated OK by a total of 10 persons. Although 9 persons rated termite meat loaf OK, only 3 people rated it 'My best of all' meaning it was not well accepted. Termite sausage received only 3 people rating it $\mathrm{OK}$ and another 6 ruling it out as 'Not OK'. This made the product to be rated 8 in a rank of 1 to 8 . However, during second product testing, termite products were better accepted than Mayflies. The Mayfly products had stronger flavor, which is a common characteristic of lake products such as fish. Termite products had mild flavor and thus amenable to different common food flavors. The participants observed that given a choice, they would opt for these insect items relative to other conventional products in the market due to their aroma, taste, and nutritional value.

Respondents who were familiar with the insects gave their opinion based on their prior knowledge of traditional methods of preparation. They were asked to compare the new products with their previous experiences. Verbal responses from the participants were encouraged. A team of six trained panelists, who freely mingled and interacted with the participants as they sampled out the new products, particularly observed facial expressions and other body language. A follow-up survey with a list of five randomly selected persons within the university from the list of participants was done for further insights into individual opinions of the products. However, this follow-up did not yield any different results from those recorded earlier in the larger audience. All the five respondents confirmed that the products were all acceptable and worth packaging for longer shelf life.

It was interesting to note that the respondents, who were familiar with termites, rated its products higher than those of Mayflies. On the other hand, those persons familiar with lake flies also rated Mayfly products higher than of termites. All necessary basic safety rules for entomophagy to minimize possible biases and unwanted reaction were observed as discussed below.

\section{Ethical considerations}

All necessary ethics and consumer rights were observed during the product testing and evaluation. Participants who had previously eaten the insects in any form (cooked or raw as commonly done by many villagers) were particularly encouraged to try the new prototype products for comparison purposes. This provided a basis for comparison and to minimize possible negative bias on entomophagy among first time users. Participants with prior allergic reaction to consumption of termites or Mayflies were discouraged from trying the samples. Among the sample of participants, there were only two people who observed that they had experienced throat irritation when they first ate raw or roasted termites. None of the participants reported or claimed any allergic reactions to eating the sample products of this project. 


\section{DISCUSSION}

Several communities within the Lake Victoria region regularly collect and eat termites in the raw form directly as the insects emerge from the holes, or slightly salt and roast them before eating. Termite crackers, therefore, received the most favorable response because majority of the respondents were already familiar with termites as food items. The Mayfly crackers were given the second position because few respondents were familiar with the insects as edible.

\section{Acceptability of the processed products}

Organoleptic tests and in particular palate tests done in the laboratory with staff yielded mixed reactions from a wide variety of people. Purposive sample to include persons not from the lake region but working and residing in Maseno town was done. Maseno University is situated within the Lake Victoria region in Kenya. Most of its junior staff, therefore, comes from the surrounding villages where termites are normally gathered and eaten, whenever the insects are in season. Many other respondents also came from the lakesides where lake flies are available during the rainy seasons. This population gave a valuable and a unique combination of panel of product testers, as consumption of these insects was not new to them. Few participants were members of other communities not from the lake region, hence, not familiar with the insects. Up to $65 \%$ of the respondents that tried the products in the laboratory preferred the new products to the traditional methods of servings. Two participants commented: 'insects will always be insects regardless of how they are prepared or served'. This was a true opinion of bias as has been reported by many other entomophagy researchers $[1,6]$.

Nevertheless, the products were all highly rated in taste and flavor, smell, texture, and appearance. Some respondents had a mixed feeling about the color of meat loaf and sausages. They observed that the natural black color (of Mayflies) was not appealing to the eyes because consumers are normally used to reddish-brown color for meat products. This was considered a momentary hindrance to the acceptability test because changing the appearance of the products may be done during product improvement stages for commercialization.

Increasing number of research papers suggest reduced consumption of red meat due to health reasons [18, 19]. Consumption of insects could be a healthier option. One researcher intimates that in the absence alternative sources of food, it is safer to eat insects in the jungle than wild plants [1]. Given the changes in lifestyle, insect products may be highly demanded by health conscious individuals. These products would make better protein source than red meat for many health conscious consumers who practice entomophagy. This was a positive feedback that may be utilized to encourage commercialization of Termites and Mayflies in the lake region.

During data collection, we learnt from the villagers that emergence of Mayfly is affected by lakeshore activities. When the waters are dirty, Mayflies migrate to other clean shores. This makes harvesting difficult because they emerge and perch on 
inaccessible shores where villagers cannot reach for harvesting. This confirms that Mayflies are sensitive to dirty waters and emerge only from clean lakeshores without contamination [20, 21, 22]. This makes such insects fairly hygienic aquatic products relative to several lake and ocean fishes. Contamination is only possible at the point of harvesting and processing and this can be improved with due care as necessary.

In the same token, termites have been reported to be sensitive to harmful chemicals in the ground and burrow low in the grounds to form their nests [23]. Mounts treated by insecticides may not realize the sexual winged termites that are harvested for human consumption. Through experience, villagers have learnt that virgin land mounds yield more termites than others. They are, therefore, often watchful for untreated grounds for the nuptial flights. By default, communities who collect termites and Mayflies often get clean and hygienic insects fit for human consumption. The Lake Victoria region villagers who assisted in collection of the samples for this study claim that rarely do humans react negatively to consumption of lake flies. This attests to safety of consuming the insect.

\section{Why termites and lake flies?}

The elate termites, which are the edible stage of the Isoptera termitidae are popularly referred to as white ants. Similarly as mentioned above, all edible lake flies are collectively (even though incorrectly) called Mayflies. Therefore, the insects in this project are referred to as simply termites and Mayflies to conform to the local language around the lake region.

Mayflies and termites are found in less marginal areas around the lake basin. The study focused on these two insects because these are among the few available natural resources, which can be used for wealth creation even in marginal areas.

\section{Food safety and entomophagy}

There are certain basic rules to be followed in insect consumption [17]. The insects must be caught alive and from healthy environments and should be processed immediately because they have a tendency to rapidly deteriorate. The storage is also critical. Villagers normally process and store them dry.

During product trials, few participants reported reacting to termite wings. The nature of the insect wings is such that tiny pieces often stick around the throat and cause unpleasant cough. Literature also showed that certain parts of insects such as the spiny legs, wings or hairy skins found in crickets, caterpillars and large grasshoppers, must be treated with caution to avoid stomach upsets [6].

Literature also show that consumption of certain insects may cause bodily harm during certain physiological conditions such as famine when a severely malnourished body may not be able to tolerate foods rich in thiamin [6]. This setback could be overcome by processing the insects by mixing with other ingredients (such as flour, sugar, eggs or bread crumbs) as demonstrated in this study. 
Yield per mound varies with the species of the insect and the locality. This study realized differing yields in different locations. A typical termite mound is capable of yielding up to a $1 / 4$ sack of termites in a night. This is equivalent to about $20 \mathrm{~kg}$ of fresh termites in one collection. Several collections can be made in one season. Communities that collect lake flies also reported that a total of up to $2 \mathrm{~kg}$ of fresh lake flies from one swarm can be collected in one morning.

With the current global concerns about food contamination, consumers are increasingly searching for healthy foods as mentioned above. These new products made from termites and Mayflies can be prepared and served in hotels as special tourists' attraction within the Western Tourist Circuit of Kenya and other areas where the insects are available to promote food and culture ecotourism. Entomophagy has potential in gastronomy in the food service industry, which can be a major income earner for many poor villagers as is the case in Thailand and other Eastern countries [1, 4, and 24]. Based on formulations and processing techniques, the products have potentials for longer shelf life. This may enable them to be available in the supermarkets for a wider audience.

As mentioned above, there is consensus that insects are nutritious and should be encouraged as human food. However, there are few who have not overcome the fear of eating insects (entophobia) [25]. Entomophagy has potentials for commercial value, particularly where many people are searching for healthy foods. Several economic reasons and food values have been identified to support consumption of insects, not only in poor nations but among the rich and developed nations as well. Japanese have refined the art of cooking of insects by using several food additives such as soy sauce [26]. This made consumption of insects fairly acceptable in certain Eastern communities. An African cookery book with authentic recipes from East Africa has been proposed [27]. With increased acceptability, such documents will find their place on many kitchen shelves. The Japanese cooking methods contrast the African ones that use limited spices and food additives. However, additional research on insects as human food needs to be done because a lot is yet to be explored in entomophagy [16].

The last quarter of the $20^{\text {th }}$ century saw several communities in Africa suffer famine and occasional food shortage due to climatic changes [11]. The century not only experienced the problems of decreased rates of food supply but also increased number of people to feed. Lack of food has been made worse because increasing number of people experience inadequate food variety. For example, fewer people eat insects and those who eat them, do not consider them a major part of their diet worth investing resources in. Edible insects are traditional foods in many cultures in western and central Africa [7] and they are also popular among the people living within the lake region in Kenya [8] so they should be reared for their high nutritional value. The Western and Eastern societies have tried introducing insect cuisines but with limited success [26, 28]. Even those who agree that insects are delicious are reluctant to eat them [25]. The Japanese have introduced insect cuisine in restaurants and therefore ordering an insect dish is normal [26]. Trends in eating insects are also slowly 
changing in the Western societies. This was demonstrated by the Entomological Society of America (ESA) Insect Expo, where Purdue University, USA prepared insect cuisine and people sampled interesting dishes [28]. Several entomophagy websites have also indicated that insect cuisines are becoming common and popular with health conscious individuals. The few edible insects that are available have become a luxury food in restaurants $[6,26]$.

Several people cite seasonality of insects as the major hindrance to consumption, which makes this source of food to be unpredictable most of the time. Ayieko $[8,9]$ has discussed insects as source of nutrients along with traditional and cultural value of lake flies. Nevertheless, termites and lake flies are in plenty during their seasons but improved technology for their collection and processing is the major challenge for modern table serving.

\section{CONCLUSION AND RECOMMENDATIONS}

Termites and Mayflies are accepted within the lake region as edible and have high potential for commercialization. The processed products positively influenced acceptability of entomophagy among different socioeconomic classes around Maseno University in Kenya. The crackers, in particular, can make a better snack than regular biscuits for many children. Food colors may be used to enhance the natural black color of Mayfly products. Mayfly has a unique flavor, which lends itself well to making meat products. This is a unique characteristic of the insect, which can be explored in the food industry.

Although, entomophagy has been trivialized as important food, insects can play a role in food security and income generation of the lake region communities. This is major step towards commercialization of the insects. With planned community mobilization, the positive attitude is incentive enough to make them seek to protect the sources of the insects and encouraging protection of the insect fauna may thus be made easier.

It is, therefore, concluded that processing insects for current eating habits enhances the value of entomophagy. As such, entomophagy will no longer be a survival tactic for the poor but a food habit for the health conscious individuals, the food for the future. 
Table 1: Distribution of points as awarded by respondents and rank ordering of the processed products based on taste and preference $(\mathrm{N}=35)$

\begin{tabular}{|c|c|c|c|c|c|c|}
\hline Line of processed products & \multicolumn{6}{|c|}{ Product Ratings by Number of Persons (Testers) } \\
\hline Presented to respondents & $\mathrm{OK}$ & My & Not & Cumulative & Total & Rank \\
\hline At different times* & A & $\begin{array}{c}\text { Best } \\
\text { B }\end{array}$ & $\begin{array}{l}\text { OK } \\
\text { C }\end{array}$ & $\mathrm{A}+\mathrm{B}-\mathrm{C}$ & $\begin{array}{l}\text { No. of } \\
\text { Testers }\end{array}$ & Order \\
\hline Mayfly sausages & 8 & 6 & 2 & 12 & 16 & 6 \\
\hline Termite sausages & 3 & 3 & 6 & 0 & 12 & 8 \\
\hline Mayfly crackers & 8 & 8 & 1 & 15 & 17 & 2 \\
\hline Termite crackers & 10 & 10 & 3 & 17 & 23 & 1 \\
\hline Mayfly muffins & 6 & 8 & 2 & 12 & 16 & 5 \\
\hline Termite muffins & 10 & 6 & 2 & 14 & 18 & 3 \\
\hline Termite meat loaf & 9 & 3 & 3 & 9 & 15 & 7 \\
\hline Mayfly meat loaf & 10 & 6 & 2 & 14 & 18 & 4 \\
\hline
\end{tabular}

* Respondents came in to try the products at different days of the week and month based on lab trial schedule 


\section{REFERENCES}

1. Meyer-Rochow VB, Kenichi N and B Somkhit More feared than revered: Insects and their impact on human societies (with some specific data on the importance of entomophagy in a Lotian setting). Entomol. Heute. 2007; 191-23.

2. The Bible (Torah) Foods permitted and forbidden, Leviticus 11, 1-32, New King James Version, Thomas Nelson, Inc. 1988.

3. Bodenheumer FS Insects as human food. The Hague, Netherlands. W. Junk Publishers, 1951.

4. Vane-Wright RI Why not eat insects? Bul. Entomol Res. 1991; 81: 1-4.

5. Ferreira A Saving the mopane worm: South Africa's wiggly snack in danger.

Food Insect Newsl. 1995; 8(1): 6.

6. Huis Van A Insects as food in Sub-Saharan Africa. Insect Sci. Appl. 2003; 23(3): 163-185.

7. Banjo AD, Lawal OA and EA Songonuga The nutritional value of fourteen species of edible insects in southwestern Nigeria. Afric. J. Biotechn. 2006; 5(3): 298-301.

8. Ayieko MA Nutrition value of selected species of reproductive Isoptera and Ephemeroptera within the ASAL of Lake Victoria basin. Discov. Innov. 2007; 19(2): 126-130.

9. Ayieko MA and V Oriaro Consumption, indigeneous knowledge and cultural values of lake fly species within the Lake Victoria region. Afric. J. Envir. Techn. 2008; 2(10): 282-286.

10. Paoletti MG (Ed) Ecological implications of minilivestock-potential of insects, rodents, frog and snail. USA, Science Publishers Enfiel, 2005.

11. Saunders A FAO serves up edible insects as part of food security solution. MEDIAGLOBAL. FAO, Rome, 2008 (February):2-23.

12. FAO. United Nations Food and Agriculture Organization, Agriculture:

Prevention of post-harvest food losses: Fruits, vegetables, and root crops, FAO, Rome, 1989. Available at: www.fao.org/docrep/T0073E/T0073E00.htm

13. Aworh OC After the harvest. In: University of Ibadan Inaugural Lectures, vol 1, (1992-1997). Nigeria, Ibadan University Press, 2005: 333-348.

14. Grigg D Pattern of world protein consumption. J. Geoforum. 1995; 26(1): 1-17.

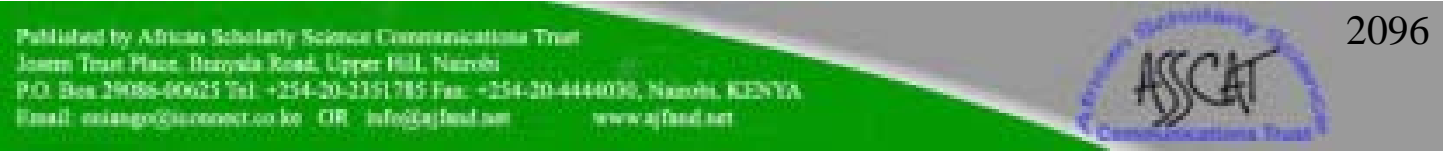


15. Odhiambo TR The use and non-use of insects. International Centre of Insect Physiology and Ecology. Nairobi. 1978: 17.

16. Gullan PJ and PS Cranston The importance and diversity of insects: An Outline of Entomology. Stanley Thornes Ltd, Oxford, 1999.

17. Kinyuru JN, Kenji GM, Njoroge SM and M Ayieko Effects of processing methods on the in vitro protein digestibility and vitamin content of edible winged termite (Macrotermes Subhylanus) and grasshopper (Ruspolia differens). Food Bioprocess Tech. DOI 10.1007/S11947-009-0264-1, Springerlink, 2009.

18. Salvini S, Hunter DJ, Sampson L, Stampfer MJ, Colditz GA, Rosner B and WC Willett Food-based validation of a dietary questionnaire: The effects of week-to-week variation in food consumption. Inter. J. Epidemio.1989; 18 (4): $858-867$.

19. Rosner $\mathbf{B}$ and $\mathbf{R}$ Gore Measurement error correction in nutritional epidemiology based on individual foods, with application to the relation of diet to breast cancer. Amer. J. Epidem. 2001; 154(9): 827-835.

20. Chindler DW Aquatic ecosystems and global ecology. In: Barnes RSK and Mann KH (Eds). Fundamentals of aquatic ecology, 2nd ed, Blackwell Science 1980: 108-121.

21. Muli JR and KM Mavuti The Benthic Macrofauna Community of Kenyan Waters of Lake Victoria. Hydrobiologia. 2001; 458: 83-90.

22. Heegaard E, Lotter AF, and HJ Birks Aquatic biota and detection of climate change: Are these consistent aquatic ecotones? J. Paleolimn. 2006; 35(3): 507518.

23. Elzinga RJ Fundamentals of Entomology. 4th ed. Insects Plants and Humans; Prentice-Hall 1997; 10: 269-320.

24. Meyer-Rochow VB Traditional food insects and spiders in several ethnic groups of Northeast India, Papua New Guinea, Australia, and New Zealand. In: Paoletti MG (Ed). Ecological implications of mini livestock-potential of insects, rodents, frog and snail. USA, Science Publishers Enfiel, 2005: 389-414.

25. Chen PP, Wongsiri S, Jamyanya T, Rinderer TE, Vongsamanode S, Matsuka M, Sylvester HA and BP Oldroyd Honey bees and other edible insects used as human food in Thailand. Amer. Entomol. 1998; 11(1): 24-28.

26. Pemberton RW and Y Tsukane Old food in New Japan. Amer. Entomol. 1995; 41(4): 227-229. 
27. Ominde M African Cookery Book. Heinemann, Nairobi, Kenya, 1988; 152pp.

28. Entomological Society of America-ESA Eating insects, BeesWax: The newsletter for ESA's youth members. Entomological Society of America. 1994; February (2): 1-2. 